\title{
Varying trends in surface energy fluxes and associated climate between 1960- 2002 based on transient climate simulations
}

\author{
Larissa Nazarenko $^{1}$ and Surabi Menon ${ }^{1,2}$ \\ ${ }^{1}$ Columbia University/NASA Goddard Institute for Space Studies, New York, NY, USA \\ ${ }^{2}$ Lawrence Berkeley National Laboratory, Berkeley, CA, USA
}

\begin{abstract}
The observed reduction in land surface radiation over the last several decades (1960-1990)---the so-called "dimming effect"---and the more recent evidence of a reversal in "dimming" over some locations beyond 1990 suggest several consequences on climate, notably on the hydrological cycle. Such a reduction in radiation should imply reduced surface temperature $\left(\mathrm{T}_{\mathrm{s}}\right)$ and precipitation, which have not occurred. We have investigated the possible causes for the above climate features using a climate model coupled to a dynamic ocean model under natural and anthropogenic conditions. To isolate the aerosol influence on surface radiation trends, we have analyzed transient climate simulations from 1960 to 2002 with and without anthropogenic aerosols. Based on a linear trend with aerosol effects included, the global mean change in the surface solar radiation absorbed over land is $-0.021 \pm 0.0033 \mathrm{Wm}^{-2} \mathrm{yr}^{-1}$. Although the overall trend is negative, we do note a reversal in dimming after 1990, consistent with observations. Without aerosol effects, the surface solar radiation absorbed over land increases throughout 1960 to 2002, mainly due to the decrease in cloud cover associated with increased greenhouse warming. In spite of a simulated increase in $\mathrm{T}_{\mathrm{s}}$ of $0.012 \mathrm{~K} \mathrm{yr}^{-1}$ for 1960 to 2002, the global mean latent heat flux and associated intensity of the hydrological cycle decrease overall, however with increases over some land locations due mainly to moisture advection. Simulated changes correspond more closely to observed changes when accounting for aerosol effects on climate.
\end{abstract}

\section{Introduction}

Over the last few decades (1960-1990), observations indicate an increase in land surface temperature $\left(\mathrm{T}_{\mathrm{s}}\right)$ of $0.013 \mathrm{~K} \mathrm{yr}^{-1}$, whereas surface radiative heating has decreased by $\sim 0.1-0.2$ $\mathrm{Wm}^{-2} \mathrm{yr}^{-1}$ [Wild et al. 2004]. An observed decline in the diurnal temperature range (DTR) is also consistent with the decrease in surface radiative heating and suggests a decrease in pan evaporation, estimated to be $\sim 90-155 \mathrm{~mm} \mathrm{yr}^{-1}$ [Roderick and Farquhar 2002, hereafter RF02]. However, the implied reduction in land precipitation is not supported by observations and may be linked to moisture advection [Wild et al. 2004] or aerosol impacts on cloud processes that not only affect cloud properties but also the underlying thermodynamics and large-scale circulation [Ramanathan et al. 2001, 2005].

Increasing greenhouse gases (GHGs) tend to warm the Earth's surface and the lower and middle troposphere. However, changes in aerosol loading and cloud cover and their interactions are the most probable causes for the reduction in absorbed solar radiation, the compensating increase in the downward longwave radiation, and reduced surface net radiation over land [Stanhill and Cohen 2001; Abakumova et al. 1996; Liepert et al. 2004; Wild et al. 2004]. In the past these trends (surface radiation and pan evaporation) were mainly reported over Europe, N. America, Soviet Union and Australia [RF02], and similar trends have now been reported over China and India [Liu et al. 2004a; Che et al. 2005; Ramanathan et al. 2005 (hereafter R05)]. Anthropogenic aerosols not only scatter (sulfate, organic carbon (OC) and nitrate) and absorb (black carbon (BC)) visible light; they also influence atmospheric heating profiles, size, lifetime 
and radiative properties of clouds. The reduction in net surface radiation and increase in lower atmospheric heating can be as much as $20 \mathrm{Wm}^{-2}$, based on results from the Indian Ocean Experiment (INDOEX) [Ramanathan et al. 2001]. Adding in this INDOEX forcing along with GHGs and the direct effect of sulfates, model simulations indicate a "dimming" of $-0.37 \pm 0.12$ $\mathrm{Wm}^{-2} \mathrm{yr}^{-1}$ for 1960-2000, which compares favorably with observations (-0.42 $\left.\mathrm{Wm}^{-2} \mathrm{yr}^{-1}\right)$ [R05]. In contrast, trends with just GHGs and sulfates do not match observed trends and suggest that absorbing aerosols found over S. Asia play a major role in regional climate and hydrological cycle changes [R05]. Over both India and China, the low-level atmospheric heating by absorbing aerosols was also found to affect low-level moisture convergence and vertical velocity rates that in turn affect circulation and precipitation [Chung et al. 2002; Menon et al. 2002; Menon 2004].

More recent evidence [Wild et al. 2005; Pinker et al. 2005] suggests an absence of "dimming" beyond 1990 at several locations (North America, western Europe, China); while "dimming" continues over India and a few other locations. This may be related to an interplay of the direct and indirect aerosol effects that no longer mask enhanced GHG effects [Wild et al. 2005]. Thus, the overall warming effects of GHGs together with changes in cloud microphysics/radiation and the thermodynamic fluxes, can act to change the climate in a nonintuitive manner. It is for these reasons that we investigate the changing climate over the last few decades via transient climate simulations that account for both aerosols and GHGs to provide some indication on the influence of aerosols on observed climate trends.

\section{Model description}

We use the NASA Goddard Institute for Space Studies (GISS) GCM model III version $\left(4^{\circ} \times 5^{\circ}\right.$ resolution, 20 vertical layers with model top at $0.1 \mathrm{hPa}$ ). The basic physics of the model is similar to the version used by Hansen et al. [2002] but includes improvements as reported in Schmidt et al. [2005]. The ocean model is a dynamic ocean model with the same horizontal resolution that makes the coupled climate model very efficient for long experiments with different forcings. The ocean model has 13 vertical levels with finer resolution at the top $100 \mathrm{~m}$. The sea ice model includes both dynamics and thermodynamics of ice cover in the Arctic and Antarctic. We employ no flux correction in the heat exchange between the atmosphere and ocean to simulate realistic climate. The model climate sensitivity for doubled $\mathrm{CO}_{2}$ is $\sim 2.7^{\circ} \mathrm{C}$ [Hansen et al. 2005], within the range $3 \pm 1^{\circ} \mathrm{C}$ for doubled $\mathrm{CO}_{2}$ inferred from paleoclimate evidence [Hansen et al. 1993].

Two experiments were performed beginning in 1880 and extending through 2002 . Although some form of industrialization may have occurred by 1880, differences between 1850 (considered a standard year for natural aerosol emissions) and 1880 simulations are minor, given the uncertainty that exists in determining aerosol distributions for either 1850 or 1880 . The first experiment (Exp A) is an ensemble of five simulations driven by increasing well-mixed GHGs, solar irradiance, stratospheric water vapor derived from methane oxidation, tropospheric and stratospheric ozone, volcanic aerosols, changes in land use, and snow/ice albedo change proportional to the local $\mathrm{BC}$ deposition [Hansen et al. 2005]. Also included are tropospheric aerosols (sulfates, OC and BC, sea-salt, dust and nitrates) and parameterized forms of the aerosol indirect effects as described in Hansen et al. [2005]. All runs of this ensemble used initial conditions at intervals of 25 years of the control experiment, which allows for the accounting of unforced model variability. The second experiment (Exp B) is a single run, similar to Exp A but includes aerosols at the 1880 level. Changes between Exp A and B may be considered as indicative of the influence of anthropogenic aerosols on climate for the time period we consider. 
For Exp A we include the uncertainty determined from the $2 \sigma$ of the five-trend mean [R05]. For Exp B we do not estimate the trend uncertainty since the GHG forcing signal is sufficiently strong. Although we mainly analyze global trends for 1960-2002, we examine trends over different time periods depending on the availability of observations (surface radiation, DTR, $\mathrm{T}_{\mathrm{s}}$, precipitation).

\section{Results}

We analyze the change, based on linear trends, in surface radiative heating and on the different components of the surface energy balance (absorbed solar radiation (ASR), downward and upward longwave radiation, sensible and latent heat fluxes). Figure 1 shows the trends in land surface ASR (the total solar flux absorbed at the ground surface) for Exp A and B for 1960-2002. In contrast to the reduced surface ASR noted in Exp A $\left(-0.021+/-0.0033 \mathrm{Wm}^{-2} \mathrm{yr}^{-1}\right.$ over land), Exp B indicates an increase of $0.0053 \mathrm{Wm}^{-2} \mathrm{yr}^{-1}$ over land. The decrease in land surface ASR noted in Exp A is similar to observations [Gilden et al. 1998; Wild et al. 1995; Liepert 2002] and modeling studies [Liepert et al. 2004; Wild et al. 1997, 1998]. The largest decrease in ASR over Southeast Asia and India follow the largest increase in total cloud amount and atmospheric water vapor (Fig. 1a, S5). However, simulated changes over some locations are much larger and some of the decrease in ASR, especially over Asia, could be a result of aerosols (especially carbonaceous aerosols) that have increased in these regions since 1950 [Novakov et al. 2003]. The decrease in ASR due to aerosols over these regions (China and India) may be inferred from the modeling studies of R05 for India that include the effects of absorbing aerosols. Our simulated values for Exp A for 1960-2000 are $-0.32 \pm 0.08 \mathrm{Wm}^{-2} \mathrm{yr}^{-1}$, comparable to values of 0.42 and $-0.37 \pm 0.12 \mathrm{Wm}^{-2} \mathrm{yr}^{-1}$ from observations and reported by $\mathrm{R} 05$, respectively. Similarly, over China, observationally based analysis by Che et al. [2005] during 1961-2000 indicate a decrease in global $\left(-0.45 \mathrm{~W} \mathrm{~m}^{-2} \mathrm{yr}^{-1}\right)$ and direct radiation $\left(-0.66 \mathrm{~W} \mathrm{~m}^{-2} \mathrm{yr}^{-1}\right)$, and in the sunshine duration $\left(-0.13 \% \mathrm{yr}^{-1}\right)$ but not in the diffuse fraction (proportion of scattered light) that actually increased by $0.17 \% \mathrm{yr}^{-1}$; indicative of the aerosol influence.

To examine the reduction in "dimming" beyond 1990 [Wild et al. 2005], we analyze our simulations for 1960-1990 and 1991-2002, as shown in Fig.2. Similar to observations, we find a reduction in land surface ASR until $1990\left(-0.024 \pm 0.0045 \mathrm{Wm}^{-2} \mathrm{yr}^{-1}\right)$ and a reversal after 1990 $\left(0.048 \pm 0.027 \mathrm{Wm}^{-2} \mathrm{yr}^{-1}\right)$, only for Exp A. In contrast, Exp B indicates increases for both time periods (0.0042 and $0.068 \mathrm{Wm}^{-2} \mathrm{yr}^{-1}$ for $1960-1990$ and $1991-2002$, respectively) mainly due to a reduction in cloud coverage with increased warming associated with increasing GHGs. Additional values for net radiation and land/ocean distribution are in Table S1. The simulated reduction in Exp A appears to be much lower than the observed reduction of $0.2-0.3 \mathrm{Wm}^{-2} \mathrm{yr}^{-1}$ in ASR reported in Wild et al. [2004]. Differences may be due to the spatial sampling (coarser spatial resolution of the model and the inhomogeneous spatial coverage of the observations); and perhaps more importantly due to the uncertainties in aerosol distributions used in the model, as well as surface albedo assumptions used to calculate absorbed surface solar fluxes.

Changes in the net radiation and the significance of the changes in both net and solar radiation for Exp A and B, are in Fig. S1 and S2, respectively. Changes in the net longwave surface flux (upward+downward) for Exp B is much smaller than for Exp A due to the offsetting of the upward and downward longwave surface fluxes for Exp B. The increase in atmospheric water vapor enhances the downward longwave flux much more effectively than it reduces the surface ASR for both Exp A and B. Tropical areas of maximum increase in atmospheric water vapor content are consistent with areas of the largest increase in incoming longwave flux. Large 
increases in both downward longwave and $\mathrm{T}_{\mathrm{s}}$ are found at high latitudes, which are associated with the positive surface albedo feedback and increased cloud cover at these latitudes.

The reduction in surface net radiation reduces the energy available for the non-radiative flux terms of the surface energy balance equation. Consequently, the sensible heat flux is reduced (mainly in Exp A) as noted in other studies [Wild et al. 1997, 1998; Roeckner et al. 1999]. The reduction in solar incidence and net loss of long-wave surface irradiance at night; in addition to the effects of aerosols and/or cloud cover, can also reduce the DTR [RF02]. Observationally based studies from Karl et al. [1993] indicate a trend of $-1.4 \mathrm{~K} / 100 \mathrm{yr}$ over all land for 1951-1990. Regional changes are larger and values of $-2.0 \mathrm{~K} / 100 \mathrm{yr}$ for 1960-2000 have been reported over China [Liu et al. 2004b]. A direct comparison between observed and modeled trends (taken over similar periods as observed trends) is at best tentative since spatial coverage between model and observations do not always coincide (land areas with available measurements cover $\sim 37 \%$ of the land mass [Karl et al. 1993]). The main point, however, is related to the negative sign in DTR reported over the last few decades. Over all land, simulated DTR trend is $0.21 \pm 0.03 \mathrm{~K} / 100 \mathrm{yr}$ globally and $-0.52 \pm 0.09 \mathrm{~K} / 100 \mathrm{yr}$ over China for Exp A. Similar values for Exp B are $-0.10 \mathrm{~K} / 100 \mathrm{yr}$ and $-0.14 \mathrm{~K} / 100 \mathrm{yr}$, respectively. Thus, simulated DTR trends are more negative (over a factor of two) with the aerosol influence.

Although one may infer a reduction in pan evaporation associated with the decline in solar irradiance and DTR from increased clouds and aerosols [RF02], Liu et al. [2004a] suggest that water conditions (vapor pressure deficit - difference in saturated and actual vapor pressure) may also influence the sensitivity of pan evaporation to solar irradiance, since the spatial patterns of changes in pan evaporation, precipitation and solar irradiance were not always consistent. While we are not able to infer changes in pan evaporation or the vapor pressure deficit with our present simulations, we find that the spatial patterns of changes in precipitation and surface radiation are not always consistent. Wild et al. [2004] speculate that moist air advection may be responsible for the increased intensity of the hydrological cycle over extratropical land areas. However, recent observational analysis of terrestrial precipitation over most land areas for 19502000 from Beck et al. [2005] indicates no significant trend. Simulated precipitation trends for the same time period over land are $-0.012 \pm 0.018 \mathrm{~mm} \mathrm{yr}^{-1}$ and $0.024 \mathrm{~mm} \mathrm{yr}^{-1}$ for Exp A and B, respectively. Although the general trend in precipitation is negative for Exp A, an increase over south-eastern Asia, consistent with observations [Xie and Arkin 1997], is seen for both Exp A and B. The increase may be explained by strong easterlies (stronger in Exp B) from the subtropical Pacific Ocean that bring in more moisture from areas with increasing sea surface temperature. The stronger southerly atmospheric flow over the northern Indian Ocean may also be the reason for enhanced precipitation over India. (Details on precipitation changes over India are in Fig. S3). However, as shown in Fig. S3, simulated precipitation changes can be subject to a large uncertainty. Thus, although we simulate a decreasing trend in precipitation for 1950-2000 for Exp A, increases over some locations appear to be mainly from moisture advection.

In addition, we note that the trend in $\mathrm{T}_{\mathrm{s}}$ for 1960-2002 for Exp B is $0.007 \mathrm{~K} \mathrm{yr}^{-1}$ over land and $0.018 \mathrm{~K} \mathrm{yr}^{-1}$ globally; whereas observed trends [Hansen et al. 1999] are 0.0053 $\pm 0.0012 \mathrm{Kyr}^{1}$ over land and $0.012 \pm 0.0028 \mathrm{~K} \mathrm{yr}^{-1}$ globally (Fig. S4). Similar to observations, Exp A values are $0.0047 \pm 0.0007 \mathrm{~K} \mathrm{yr}^{-1}$ over land and $0.012 \pm 0.0014 \mathrm{~K} \mathrm{yr}^{-1}$ globally. This reduced trend in $\mathrm{T}_{\mathrm{s}}$ for Exp A may be directly related to the cloud cover increase in Exp A $\left(0.0033 \pm 0.0035 \% \mathrm{yr}^{1}\right.$ globally) compared to the strong reduction $\left(-0.011 \% \mathrm{yr}^{-1}\right)$ seen in Exp B (Fig. S5). For Exp A, cloud cover trends increase from 1960-1990 and then decrease from 1991-2002 (Fig. S6); consistent with the changes in "dimming" trends. However, cloud cover trends are difficult to 
interpret and have a high degree of variability in model simulations. In Exp A we include the increase in simulated cloud optical depth and cloud lifetime [Houghton et al. 2001] via parameterized treatments of the aerosol indirect effects [Hansen et al. 2005]. In contrast, cloud cover in Exp B is heavily reduced due to strong warming. As a result, the surface consistently experiences stronger radiative heating as seen in Fig. 2. The larger increase in water vapor, an ability of a warmer atmosphere to hold more moisture, contributes even more to stronger surface and tropospheric warming since water vapor acts extensively as a GHG in this situation.

\section{Conclusion}

Overall, our simulations with aerosol effects added to GHG and other forcings indicate a general reduction in land surface ASR for 1960-2002: a decreasing trend for 1960-1990 followed by an increasing trend for 1991-2002, consistent with observations [Wild et al. 2005]. Without the aerosol effects, the land surface ASR indicates an increasing trend for both 1960-1990 and 1991-2002, due to the reduced cloud cover from increasing GHGs. The reversal in "dimming" trends reported for 1990 onwards over some locations may be a consequence of reduced aerosol emissions over these regions that no longer mask the GHG effect [Wild et al. 2005]. The increase in incoming longwave radiation noted; the most plausible consequence of increased GHG and water vapor loading, is consistent with previous studies on transient increase of $\mathrm{CO}_{2}$ [Wild et al. 1997]; but is lower with aerosol effects included. The simulated surface shortwave radiation over land closely follows the pattern of changes in cloud cover such that the largest reduction of surface ASR is in regions with the largest increase in cloud cover. Only in the simulation with aerosols added to GHGs do we note the reduction in surface radiation, an increase in $\mathrm{T}_{\mathrm{s}}$, and a reduction in DTR, consistent with observed trends.

The global mean latent heat flux and associated intensity of the hydrological cycle decrease despite increased GHGs when accounting for aerosols. An increase in precipitation over some regions is mainly from moisture advection (weakened with aerosol effects included), though we do not discount changes in large-scale dynamical features (such as the quasi-biennial oscillation, ENSO) that also influence circulation/precipitation. Our transient climate simulations indicate that the aerosol influence on observed climate trends over the last four decades is significant. Current uncertainties in quantifying aerosol climate effects suggest that greater emphasis be placed in simulating and representing aerosol effects on climate.

Acknowledgements: LN acknowledges support from the NASA Earth Science Research Division. SM acknowledges support from the NASA Climate Modeling projects managed by Don Anderson/Tsengdar Lee; the NASA GWEC project; LBNL's LDRD project and the DOE ARM project. This analysis was based on simulations designed by Jim Hansen and we acknowledge his role in this effort. We thank Judith Perlwitz for assistance with statistical analysis, Reto Ruedy for help with observational data and the reviewers for helpful comments.

\section{References}

Abakumova, G.M., et al. (1996), Evaluation of long-term changes in radiation, cloudiness, and surface temperature on the territory of the Former Soviet Union, J. Clim., 9, 1319-1327.

Beck, C., J. Grieser and B. Rudolf (2005), A new monthly precipitation climatology for the global land areas for the period 1951 to 2000, Climate Status Report 2004, German Weather Service, Offenbach, Germany. 
Che, H.A., et al. (2005), Analysis of 40 years of solar radiation data from China, 1961-2000, Geophys. Res. Let., 32, doi:10.1029/2004GL022322.

Chung, C.E, V. Ramanathan, J.T. Kiehl (2002), Effects of south Asian absorbing haze on the northeast monsoon and surface-heat exchange, J. Clim., 15, 2462-76.

Gilden, H., M. Wild, and A. Ohmura (1998), Means and trends of shortwave irradiance at the surface estimated from Global Energy Balance Archive data, J. Clim., 11, 2042-2061.

Hansen, J., et al. (1993), How sensitive is the world's climate? Natl. Geogr. Res. Explor., 9, 142158.

Hansen, J., et al. (1999), GISS analysis of surface temperature change, J. Geophys. Res., 104, 30997-31022.

Hansen, J., et al. (2002), Climate forcings in Goddard Institute for Space Studies SI2000 simulations, J. Geophys. Res., 107, doi:10.1029/2001JD001143.

Hansen, J., et al. (2005), Efficacy of climate forcings, J. Geophys. Res., In Press.

Houghton, J.T., G.J. Jenkins, J.J. Ephraums (Eds.) (2001), Climate Change 2001. The Scientific Basis, Cambridge Univ. Press, Cambridge/New York.

Karl, T.R., et al. (1993), Asymmetric trends of daily maximum and minimum temperature, Bull. Amer. Meteorol. Soc., 74, 1007-1023.

Liepert, B.G., et al. (2004), Can aerosols spin down the water cycle in a warmer and moister world? Geophys. Res. Let., 31, doi:10.1029/2003GL019060.

Liepert, B.G. (2002), Observed reductions of surface solar radiation at sites in the United States and worldwide from 1961 to 2000, Geophys. Res. Let., 29, doi:10.1029/2002GL014910.

Liu, B., M. Xu, M. Henderson, and W. Gong (2004a), A spatial analysis of pan evaporation trends in China, 1955-2000, J. Geophys. Res., 109, D15102, doi:101029/2004JD004511.

Liu, B., M. Xu, M. Henderson, Y. Qi, and Y. Li, (2004b), Taking China's temperature: Daily range, warming trends and regional variations, 1955-2000, J. Clim., 17, 4453-4462.

Menon, S., J. Hansen, L. Nazarenko and Y. Luo (2002), Climate effects of black carbon aerosols in China and India, Science, 297, 2250-2253.

Menon, S. (2004), Current uncertainties in assessing aerosol effects on climate, Ann. Rev. Environ. Resour., 29, 1-30.

Novakov, T., et al. (2003), Large historical changes of fossil-fuel black carbon aerosols, Geophys. Res. Let., doi:10.1029/2002GL016345.

Pinker, R.T., B. Zhang, and E.G. Dutton (2005), Do satellites detect trends in surface solar radiation? Science, 308, 850-854.

Ramanathan, V., et al. (2001), Indian Ocean Experiment: An integrated analysis of the climate forcing and effects of the great Indo-Asian haze. J. Geophys. Res., 106, 28371-28398.

Ramanathan, V., et al. (2005), Atmospheric brown clouds: Impacts on South Asian climate and hydrological cycle, Proc. Nat. Acad. Sci., 102, 5326-5333.

Roderick, M.L., and G.D. Farquhar (2002), The cause of decreased pan evaporation over the past 50 years, Science, 298, 1410-1411.

Roeckner, E., et al. (1999), Transient climate change simulations with a coupled atmosphereocean GCM including the tropospheric sulfur cycle, J. Clim., 12, 3004-3032.

Schmidt, G., et al. (2005), Present day atmospheric simulations using GISS ModelE: Comparison to in-situ, satellite and reanalysis data. J. Clim., In Press.

Stanhill, G., and S. Cohen (2001), Global dimming: A review of the evidence for widespread and significant reduction in global radiation with discussion of its probable causes and possible agricultural consequences, Agricultural Forest Meteorol., 107, 255-278. 
Wild, M., A. Ohmura, H. Gilden, and E. Roeckner (1995), Validation of GCM simulated radiative fluxes using surface observations, J. Clim., 8, 1309-1324.

Wild, M., A. Ohmura, H. Gilden, and U. Cubasch (1997), GCM simulated surface energy fluxes in climate change experiments, J. Clim., 10, 3093-3110.

Wild, M., et al. (1998), The disposition of radiative energy in the global climate system: GCM versus observational estimates, Clim. Dyn., 14, 853-869.

Wild, M., A. Ohmura, and H. Gilden (2004), On the consistency of trends in radiation and temperature records and implications for the global hydrological cycle, Geophys. Res. Let., 31, doi:10.1029/2003GL019188.

Wild, M., et al. (2005), From Dimming to Brightening: Decadal Changes in Solar Radiation at Earth's Surface, Science, 308, 847-850.

Xie, P. and P.A. Arkin (1997), Global precipitation: A 17-year monthly analysis based on gauge observation, satellite estimates, and numerical model outputs, Bull. Amer. Meteor. Soc., 78, 2539-2558.

\section{Figure Legends}

Figure 1. Simulated trends in land surface absorbed solar radiation ( $\mathrm{Wm}^{-2}$ ) for 1960-2002 for (a) Exp A and (b) Exp B. The limits of trends for 1960-2002, from $-21 \mathrm{Wm}^{-2}$ to $20 \mathrm{Wm}^{-2}$, correspond respectively to the trends per year from $-0.49 \mathrm{Wm}^{-2} \mathrm{yr}^{-1}$ to $0.47 \mathrm{Wm}^{-2} \mathrm{yr}^{-1}$.

Figure 2. Simulated trends in land surface absorbed solar radiation $\left(\mathrm{Wm}^{-2}\right)$ for 1960-1990 (left column) and 1991-2002 (right column). Upper panels are for Exp A and lower panels are for Exp B. The limits of trends for 1960-1990 (left column), from -20 $\mathrm{Wm}^{-2}$ to $20 \mathrm{Wm}^{-2}$, correspond respectively to the trends per year from $-0.65 \mathrm{Wm}^{-2} \mathrm{yr}^{-1}$ to $0.65 \mathrm{Wm}^{-2} \mathrm{yr}^{-1}$. The limits of trends for 1991-2002 (right column), from $-24 \mathrm{Wm}^{-2}$ to $24 \mathrm{Wm}^{-2}$, correspond respectively to the trends per year from $-2.0 \mathrm{Wm}^{-2} \mathrm{yr}^{-1}$ to $2.0 \mathrm{Wm}^{-2} \mathrm{yr}^{-1}$. 


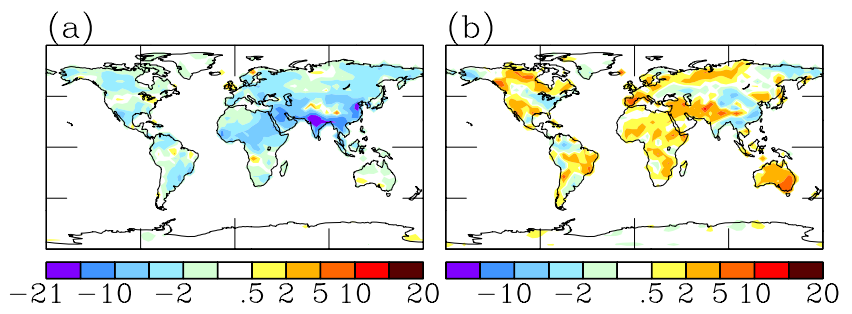

Figure 1. Simulated trends in land surface absorbed solar radiation $\left(\mathrm{Wm}^{-2}\right)$ for 1960-2002 for (a) Exp A and (b) Exp B. The limits of trends for 1960-2002, from $-21 \mathrm{Wm}^{-2}$ to $20 \mathrm{Wm}^{-2}$, correspond respectively to the trends per year from $-0.49 \mathrm{Wm}^{-2} \mathrm{yr}^{-1}$ to $0.47 \mathrm{Wm}^{-2} \mathrm{yr}^{-1}$.

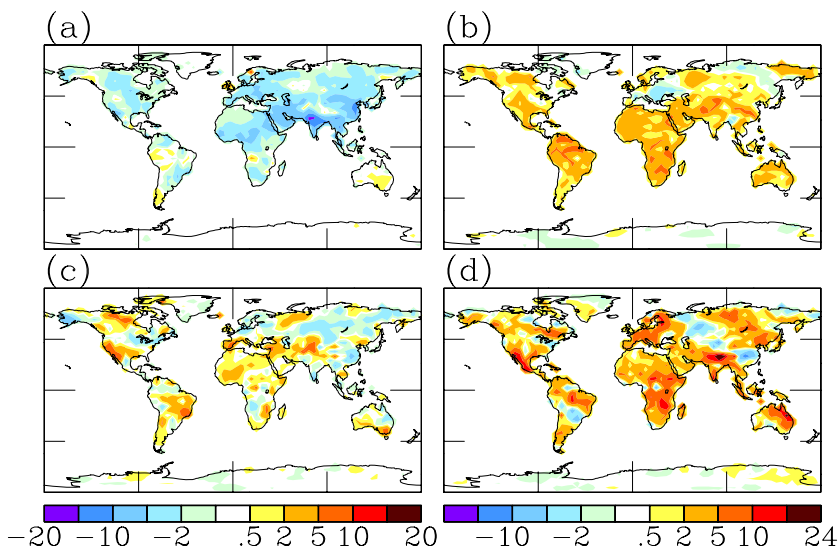

Figure 2. Simulated trends in land surface absorbed solar radiation $\left(\mathrm{Wm}^{-2}\right)$ for 1960-1990 (left column) and 1991-2002 (right column). Upper panels are for Exp A and lower panels are for Exp B. The limits of trends for 1960-1990 (left column), from $-20 \mathrm{Wm}^{-2}$ to $20 \mathrm{Wm}^{-2}$, correspond respectively to the trends per year from $-0.65 \mathrm{Wm}^{-2} \mathrm{yr}^{-1}$ to $0.65 \mathrm{Wm}^{-2} \mathrm{yr}^{-1}$. The limits of trends for 1991-2002 (right column), from $-24 \mathrm{Wm}^{-2}$ to $24 \mathrm{Wm}^{-2}$, correspond respectively to the trends per year from $-2.0 \mathrm{Wm}^{-2} \mathrm{yr}^{-1}$ to $2.0 \mathrm{Wm}^{-2} \mathrm{yr}^{-1}$. 


\section{Supplementary Figures:}

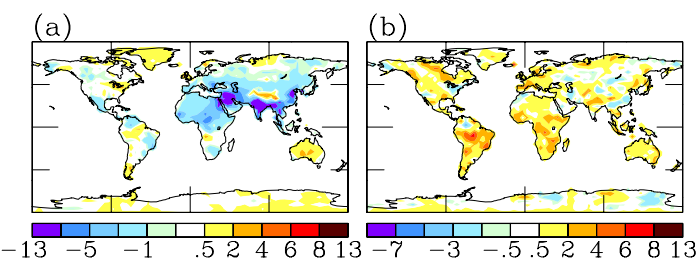

Figure S1. Trends in land surface net radiation $\left(\mathrm{Wm}^{-2}\right)$ for (a) Exp A and (b) Exp B for 1960-2002. The limits of trends for 1960-2002, from $-13 \mathrm{Wm}^{-2}$ to $13 \mathrm{Wm}^{-2}$, correspond respectively to the trends per year from $-0.30 \mathrm{Wm}^{-2} \mathrm{yr}^{-1}$ to $0.30 \mathrm{Wm}^{-2} \mathrm{yr}^{-1}$. Global averaged land values are -0.0093 and $0.0067 \mathrm{Wm}^{-2} \mathrm{yr}^{-1}$ for Exp A and $\mathrm{B}$, respectively. Differences between net radiation and absorbed solar radiation shown in Fig.1 for Exp $\mathrm{A}$ and $\mathrm{B}$ indicates that the sum of the upward and downward longwave fluxes (that gives us the net longwave flux) almost cancel each other for Exp B, whereas for Exp A, a small difference is found. This can be attributed to both the effects of water vapor and the surface skin temperature that offset the downward and upward longwave fluxes much more effectively for Exp B than for Exp A.

(a)
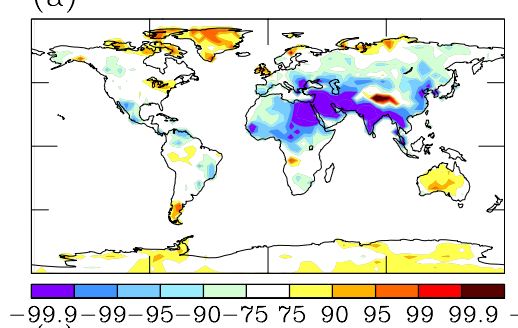

(c)

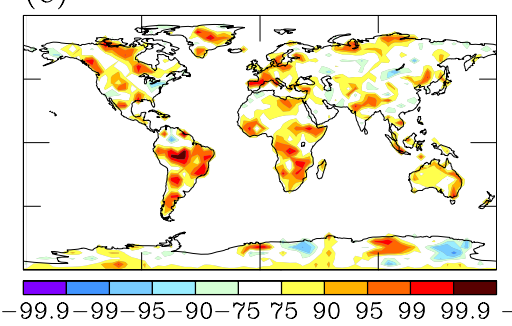

-99.9-99-95-90-75 7590959999.9 (b)

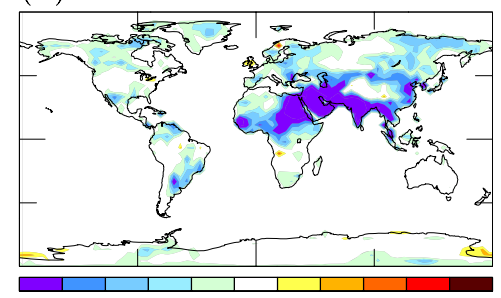

-99.9-99-95-90-757590959999.9

(d)

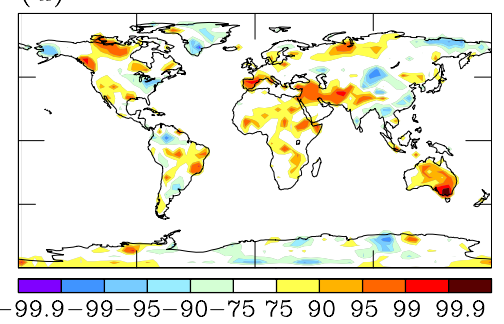

Figure S2. Significance of simulated trends in net radiation (left column) and absorbed solar radiation (right column) over land surfaces. Upper panels are for Exp A and lower panels are for Exp B. The color bars indicate the confidence intervals. 


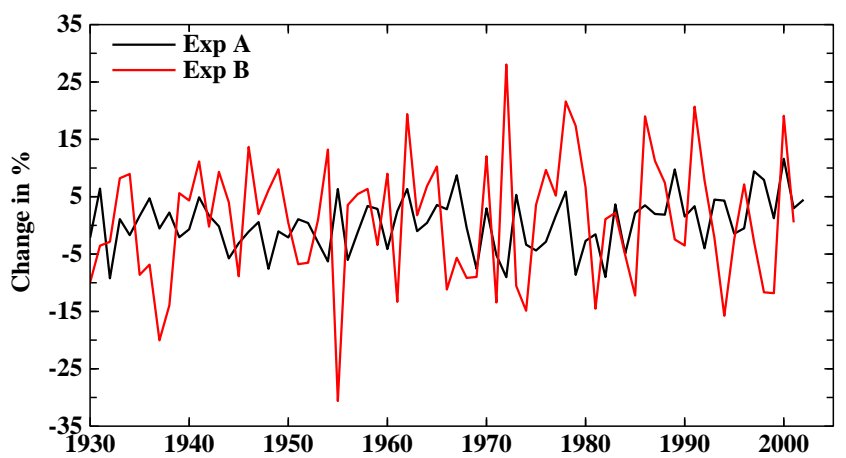

Figure S3. Precipitation anomalies over 1930-2000 for June to September (relative to the 1930-1960 average) over India for Exp A and Exp B. Over the 1930-2000 time period precipitation anomalies (from the 1930-1960 average) over India (JuneSeptember) indicate a reducing trend $\left(-0.070 \pm 0.042 \% \mathrm{yr}^{-1}\right)$ [R05], while results from Exp A and B over the same period indicate large interdecadal variability with slightly increased trends noted for Exp A and Exp B $\left(0.055 \pm 0.064 \% \mathrm{yr}^{-1}\right.$ and $0.045 \% \mathrm{yr}^{-1}$ respectively). The inconsistency between model and observed trends may be due to inaccurate representation of the aerosol effects on precipitation (implicitly accounted for by parameterizations that just include increased cloud cover due to aerosol effects but not reduced precipitation due to reduced droplet size or the feedback between aerosols and clouds), which is an uncertain factor in model simulations [Menon et al. 2003; Liepert et al. 2004]. 


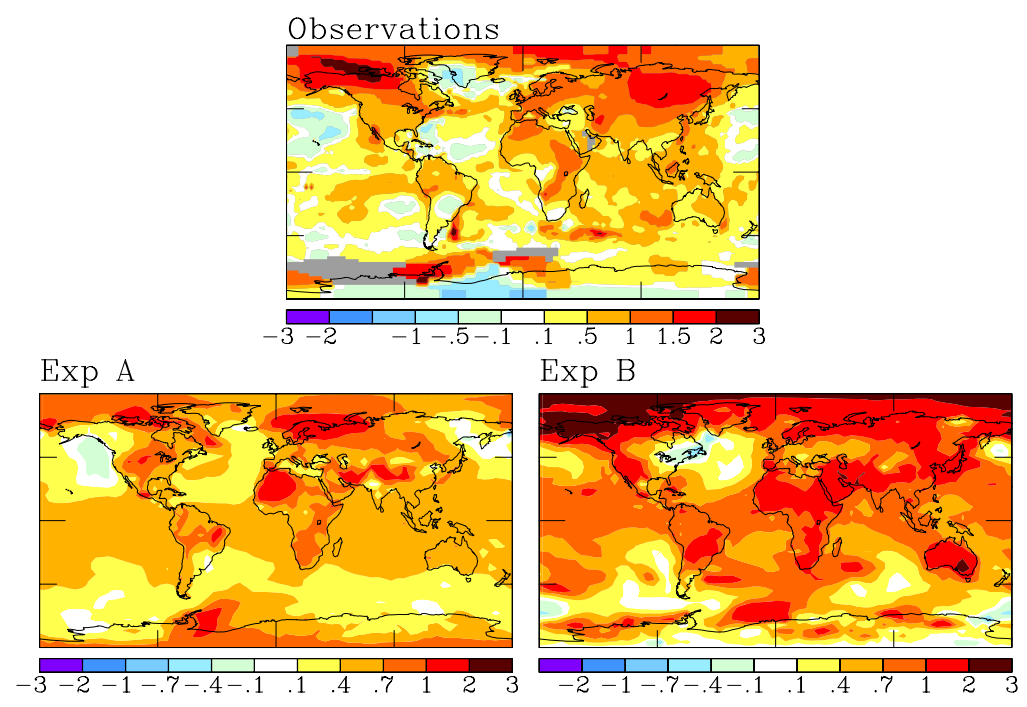

Figure S4. Trends in surface temperature (K) for observations [Hansen et al. 1999], Exp A and Exp B for 1960-2002. The limits trends for 1960-2002, from $-3 \mathrm{~K}$ to $3 \mathrm{~K}$, correspond respectively to the trends per year from $-0.07 \mathrm{~K} \mathrm{yr}^{-1}$ to $0.07 \mathrm{~K} \mathrm{yr}^{-1}$. 

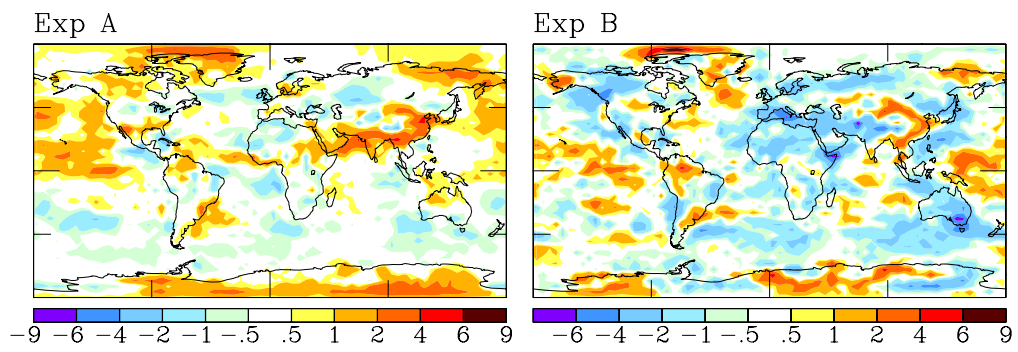

Figure S5. Trends in total cloud cover (\%) for Exp A and Exp B for 1960-2002. The limits of trends for $1960-2002$, from $-9 \%$ to $9 \%$, correspond respectively to the trends per year from $-0.21 \% \mathrm{yr}^{-1}$ to $0.21 \% \mathrm{yr}^{-1}$.
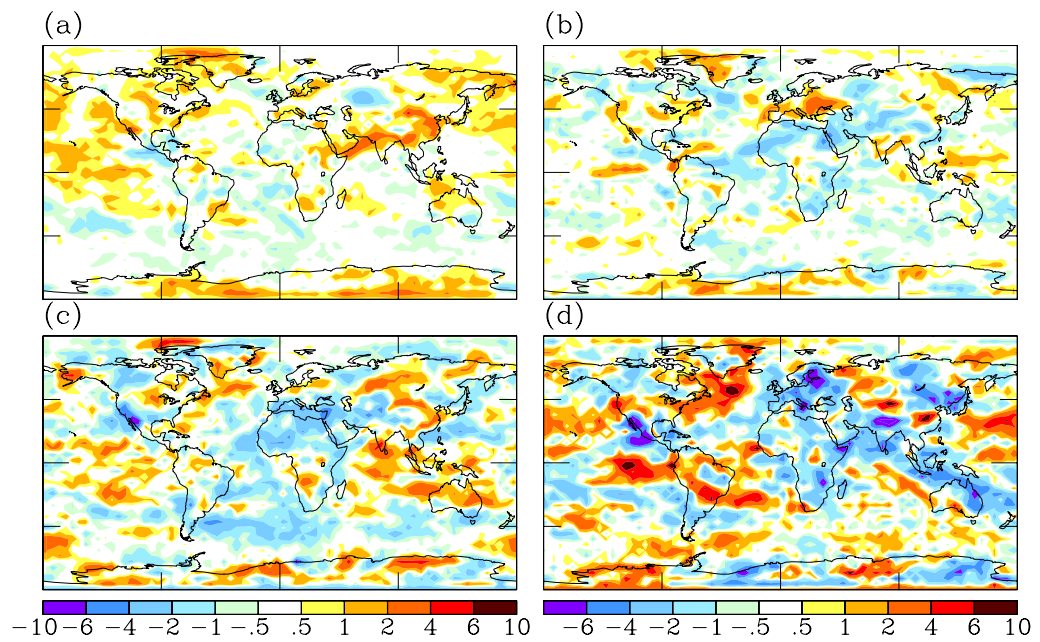

Figure S6. Simulated trends in total cloud cover (\%) for 1960-1990 (left column) and 1991-2002 (right column). The limits of trends for 1960-1990 (left column), from $-10 \%$ to $10 \%$, correspond respectively to the trends per year from $-0.32 \%$ $\mathrm{yr}^{-1}$ to $0.32 \% \mathrm{yr}^{-1}$. The limits of trends for 1991-2002 (right column), from $-10 \%$ to $10 \%$, correspond respectively to the trends per year from $-0.83 \% \mathrm{yr}^{-1}$ to 0.83 $\% \mathrm{yr}^{-1}$. Upper panels are for Exp A and lower panels are for Exp B. Global averaged values of trends are $0.0048,-0.019,-0.0097,-0.031 \% \mathrm{yr}^{-1}$ for a, b, c and d respectively. 


\section{Supplementary Table:}

Table S1: Changes based on trends in values for net and absorbed solar radiation over land and ocean for Exp A and B for the different time periods.

\begin{tabular}{ccccc}
\hline & \multicolumn{2}{c}{$1960-1990$} & \multicolumn{2}{c}{$1991-2002$} \\
Land & Ocean & Land & Ocean \\
\hline $\begin{array}{c}\text { Net Radiation }\left(\mathrm{Wm}^{-2} \mathrm{yr}^{-1}\right) \\
\text { Exp A } \\
\text { Exp B }\end{array}$ & $-0.010 \pm 0.0026$ & $0.017 \pm 0.0039$ & $0.039 \pm 0.00026$ & $0.19 \pm 0.017$ \\
Solar Radiation (Wm $\left.{ }^{-2} \mathrm{yr}^{-1}\right)$ & 0.0077 & 0.045 & 0.041 & 0.20 \\
Exp A & $-0.024 \pm 0.0045$ & $-0.011 \pm 0.0039$ & $0.048 \pm 0.027$ & $0.15 \pm 0.03$ \\
Exp B & 0.0042 & 0.017 & 0.068 & 0.16 \\
\hline
\end{tabular}

\section{Supplementary References:}

Menon, S., et al. (2003), Evaluating cloud-aerosol process parameterizations with single column models and ACE-2 cloudy column observations, J. Geophys. Res. 108, doi:10.1029/2003JD003902. 